\title{
Relationship of QTAIM and NOCV Descriptors with Tolman's Electronic Parameter
}

\author{
Tímea R. Kégl, ${ }^{1,2,3}$ László Kollár, ${ }^{1,2,3}$ and Tamás Kégl 1,2,3 \\ ${ }^{1}$ Department of Inorganic Chemistry, University of Pécs, Ifjúság útja 6, 7624 Pécs, Hungary \\ ${ }^{2} J a ́ n o s$ Szentágothai Research Center, Ifjúság útja 34, 7624 Pécs, Hungary \\ ${ }^{3}$ MTA-PTE Research Group for Selective Chemical Syntheses, Pécs, Hungary \\ Correspondence should be addressed to Tamás Kégl; tkegl@gamma.ttk.pte.hu
}

Received 30 April 2016; Revised 8 August 2016; Accepted 17 August 2016

Academic Editor: Reinout Meijboom

Copyright @ 2016 Tímea R. Kégl et al. This is an open access article distributed under the Creative Commons Attribution License, which permits unrestricted use, distribution, and reproduction in any medium, provided the original work is properly cited.

The $\sigma$-donor properties of various P-donor ligands have been studied at the PBEPBE level of theory, which has proved to be accurate in computing the symmetric carbonyl stretching frequencies in nickel(0)-tricarbonyl complexes containing P-donor ligands. The delocalization index from the QTAIM methodology and the energy component associated with the NOCV deformation density representing the donor interaction give the best correlation with Tolman's electronic parameters, whereas the electron density at the bond critical point and the Wiberg bond index are connected with the donor strength of the ligands to a lesser extent.

\section{Introduction}

In the last decades the continuous increase in computing performance as well as the discovery of several computational principles and effective algorithms has resulted in a huge leap in terms of accuracy and speed of quantum chemical methods. Computational chemistry is now feasible to handle many catalytic reactions with acceptable to excellent agreement with experimental observations. Moreover, a theoretical project is often faster than an experimental one and is sometimes the only way to obtain certain data, such as the evaluation of partial charges within a molecule or the geometry of transition state structures.

The importance of selective catalysts has become enormous in drug discovery and green chemistry, for instance, in reducing waste, simplifying the processes, and promoting possibility for using renewable resources. Asymmetric catalysis is one of the most economic and environmentally friendly ways to produce enantiopure fine chemicals. But in spite of the importance of homogeneous catalysis and the rapid development of computational facilities, most organometallic catalysts still have been discovered through serendipity rather than systematic design.

Phosphines, phosphites, and other P-donor ligands are of crucial importance in carbonylation and in many other reactions catalyzed by transition metal (TM) compounds. Changing the coordinated ligands is a powerful way of modifying the properties of transition metal complexes, especially those active in homogeneous catalysis. Their structural variation allows fine tuning of catalytic activity and chemo-, regio-, and enantioselectivity. It has long been known that varying the substituents can cause changes in the behavior of the uncoordinated ligands as well as their TM complexes. Information about the nature of transition metal-phosphorus bond is crucial for characterization of catalytically active compounds and for the tuning of their properties in order to develop more efficient catalysts. Phosphines bound to TMcarbonyl complexes can be ranked in an electronic series based on CO stretching frequencies $[1,2]$. As the different behavior of various phosphines cannot be explained entirely in terms of their electronic character, Tolman introduced the ligand cone angle as well, as a fundamental descriptor for ligand steric effects. Employing computational chemistry may bring the advantage that determining the properties of ligands and their TM complexes is usually faster and cheaper by using quantum chemical methods. Calculating Tolman's electronic parameter (TEP), for instance, is also much safer because the work with the poisonous $\mathrm{Ni}(\mathrm{CO})_{4}$ complex can be avoided. It should be noted, however, that 
definite progress has also been made in the field of the experimental determination of electronic parameters. For instance, the Rh-Vaska type of complexes is easy to synthesize and strong correlation has been established between the $v(\mathrm{CO})$ of $\mathrm{Ni}(\mathrm{CO})_{3}\left(\mathrm{PR}_{3}\right)$ and the corresponding $\mathrm{RhCl}(\mathrm{CO})\left(\mathrm{PR}_{3}\right)_{2}$ complexes [3]. Moreover, the rate of $\mathrm{Se}=\mathrm{P}$ bond formation from $\mathrm{KSeCN}$ and tertiary phosphines is sensitive over 5 orders of magnitude and reveals a strong correlation with the electronic properties of the P-donor ligands [4].

In the recent years several attempts have been made for employing theoretical methods to characterize the donor and acceptor properties of phosphines and other (mainly P-donor) ligands. These methods can be divided into two categories. The first group deals only with the isolated ligand, focusing its electronic and steric properties, neglecting the influence of the metal containing fragment. As a prominent example, the molecular electrostatic potential at the lone pair of the phosphorus atom should be emphasized, which correlates well with TEP, according to Suresh and Koga [5]. Moreover, the method known as quantitative analysis of ligand effects (QALE) relies on experimental data of known ligands and provides the resolution of net donating ability into QALE parameters [6, 7]. The second category uses approaches which focus on the entire transition metal complex, thereby including the possibility of scrutinizing ligand-ligand effects as well.

The goal of the paper is to investigate the relationship of descriptors of some popular electronic structure methods with Tolman's electronic parameter which is still the most generally accepted method to measure the net donating ability of a ligand. In this context, the delocalization index and the electron density in the bond critical point from the Quantum Theory of Atoms in Molecules (QTAIM) methodology [8] are compared with the Wiberg bond index of the Ni-P bond and with the bonding energy and the energy component of the donor interaction derived from the Natural Orbitals for Chemical Valence (NOCV) methodology [9].

\section{Computational Details}

All structures were fully optimized at the DFT/PBEPBE level of theory [10] with ultrafine grids employing the Gaussian 09 suite of programs [11]. The PBEPBE functional was already employed successfully for computing Tolman's electronic parameters [12]. For nickel the def2-TZVP was used, whereas for the other atoms the def2-SVP basis sets were used [13] for geometry optimizations (denoted as PBEPBE/def2TZVP(def2-SVP)) while full triple- $\zeta$ basis set (def2-TZVP) has been employed for the single-point energy structure calculations. Local minima were identified by the absence of the negative eigenvalues in the vibrational frequency analyses. For the QTAIM (Quantum Theory of Atoms In Molecules) calculations [8] the AIMAll software package was utilized [14]. Natural bond orbital (NBO) analyses [15] have been performed by the GENNBO 5.0 program and Wiberg bond indices were calculated on natural atomic orbital basis. For the ETS-NOCV calculations [9] the ADF 2012 software $[16,17]$ has been employed. The cone angles of various P-donor ligands have been determined utilizing the steric
TABLE 1: Experimental [1, 2, 21] (in $\mathrm{CH}_{2} \mathrm{Cl}_{2}$ ) and computed $\mathrm{CO}$ stretching frequencies (in $\mathrm{cm}^{-1}$ ), Ni-P distances (in $\AA$ ), and computed steric parameters $\left(\Theta\right.$, in degree) for $\mathrm{Ni}(\mathrm{CO})_{3} \mathrm{~L}$ complexes.

\begin{tabular}{|c|c|c|c|c|}
\hline Ligand & $v(\mathrm{CO})_{\exp }$ & $\nu(\mathrm{CO})_{\mathrm{calc}}$ & $r(\mathrm{Ni}-\mathrm{P})$ & $\Theta$ \\
\hline $\mathrm{PF}_{3}$ & 2111 & 2117 & 2.131 & 104 \\
\hline $\mathrm{PMe}_{3}$ & 2066 & 2073 & 2.239 & 121 \\
\hline $\mathrm{PMe}_{2} \mathrm{Ph}$ & 2067 & 2074 & 2.245 & 147 \\
\hline $\mathrm{PPh}_{3}$ & 2070 & 2077 & 2.259 & 166 \\
\hline $\mathrm{P}(\mathrm{p}-\mathrm{Tol})_{3}$ & 2067 & 2075 & 2.261 & 166 \\
\hline $\mathrm{P}(\mathrm{o}-\mathrm{Tol})_{3}$ & 2067 & 2073 & 2.301 & 202 \\
\hline $\mathrm{PCy}_{3}$ & 2060 & 2066 & 2.284 & 169 \\
\hline $\mathrm{P}^{\mathrm{i}} \mathrm{Pr}_{3}$ & 2062 & 2069 & 2.284 & 186 \\
\hline $\mathrm{P}^{\mathrm{t}} \mathrm{Bu}_{3}$ & 2056 & 2064 & 2.321 & 188 \\
\hline $\mathrm{P}\left(\mathrm{CF}_{3}\right)_{3}$ & 2107 & 2110 & 2.167 & 140 \\
\hline PTA & n.a. & 2079 & 2.228 & 115 \\
\hline $\mathrm{P}(\mathrm{OMe})_{3}$ & 2080 & 2092 & 2.186 & 168 \\
\hline $\mathrm{P}(\mathrm{OPh})_{3}$ & 2087 & 2095 & 2.175 & 185 \\
\hline
\end{tabular}

program [18] preserving the geometry of the ligands in the coordinated $\mathrm{Ni}(\mathrm{CO})_{3} \mathrm{~L}$ complexes thereby adapting the steric parameters to the molecular environment.

\section{Results and Discussion}

For the proper comparison of experimental carbonyl stretching frequencies with electronic structure descriptors a set of simple monodentate ligands has been chosen covering the range of known TEP parameters of P-donor ligands. This comprises monotertiary phosphines, phosphorus trifluoride, and phosphites, namely, $\mathrm{P}(\mathrm{OMe})_{3}$ and $\mathrm{P}(\mathrm{OPh})_{3}$. The $v(\mathrm{CO})$ $s$ and the most important structural parameters, that is, the $\mathrm{Ni}-\mathrm{P}$ bond distances of their $\mathrm{Ni}(\mathrm{CO})_{3} \mathrm{~L}$ type of complexes, are compiled in Table 1 . Because of the high conformational flexibility of the phosphite ligands [19] the global minima for phosphite complexes have been searched according to Figure 1. For both $\mathrm{P}(\mathrm{OMe})_{3}$ and $\mathrm{P}(\mathrm{OPh})_{3}$ the conformation "A" was proved to be the least favored energetically, whereas the relative free energy of conformers "B"- $D$ " fell within the range of $2 \mathrm{kcal} / \mathrm{mol}$. The most stable structure is " $\mathrm{C}$ " for $\mathrm{Ni}(\mathrm{CO})_{3}\left(\mathrm{P}(\mathrm{OPh})_{3}\right)$ whereas it is conformer " $\mathbf{B}$ " for $\mathrm{Ni}(\mathrm{CO})_{3}\left(\mathrm{P}(\mathrm{OMe})_{3}\right)$.

The set of ligands has also been extended with $\mathrm{P}(\mathrm{o}-\mathrm{Tol})_{3}$ in order to get an insight into the deviation of electronic parameters when the steric demand of the ligand has been increased significantly in comparison to $\mathrm{P}(\mathrm{p}-\mathrm{Tol})_{3}$. The ligand 1,3,5-triaza-7-phosphaadamantane (PTA) has also been taken into consideration because of its unique properties being a water soluble ligand with small steric bulk and fairly enhanced basicity [20].

The Ni-P distance depends not only upon the donating ability of the ligands, but also upon their steric demand; therefore no unambiguous relationship can be established between the Ni-P distances and the TEPs. It is worth noting, however, that electron withdrawing substituents on phosphorus result in shorter bonds, as seen, for instance, in $\mathrm{Ni}(\mathrm{CO})_{3}\left(\mathrm{P}\left(\mathrm{CF}_{3}\right)_{3}\right)(2.167 \AA)$ as opposed to $\mathrm{Ni}(\mathrm{CO})_{3}\left(\mathrm{PMe}_{3}\right)$ 
<smiles>[R]O[P](O[R])(O[R])[N+](=O)[O-]</smiles>

A<smiles>[R]O[P](O[R])(O[R])[N+](=O)[O-]</smiles>

B<smiles>[R]O[P](O[R])(O[R])[N+](=O)[O-]</smiles>

C<smiles>[R]O[P](O[R])(O[R])[N+](=O)[O-]</smiles>

$\mathrm{R}=\mathrm{Me}, \mathrm{Ph}$

D

Figure 1: Possible phosphite conformations in $\mathrm{Ni}(\mathrm{CO})_{3} \mathrm{~L}$ complexes.

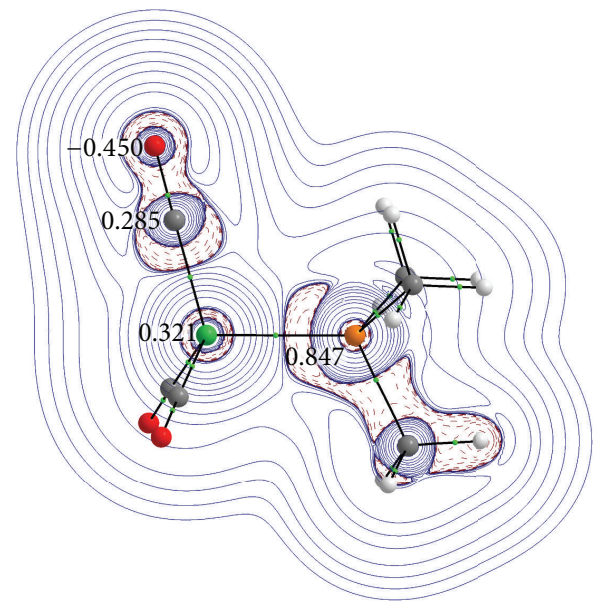

(a)

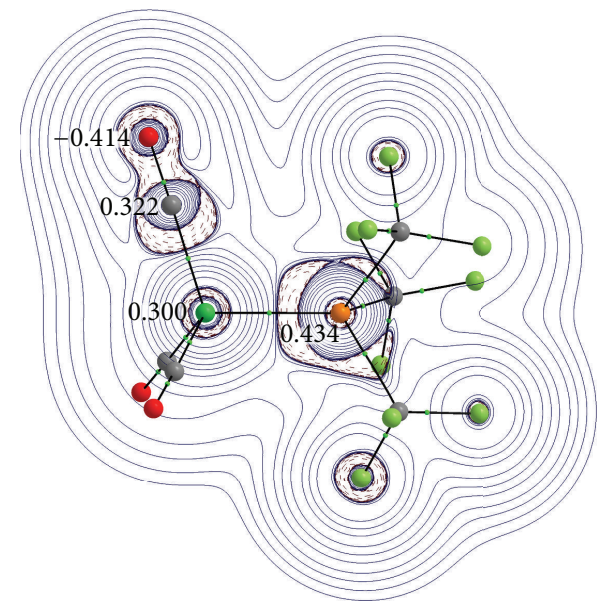

(b)

Figure 2: Natural Population Analysis (NPA) charges and the Laplacian $\left(\nabla^{2} \rho(\mathbf{r})\right)$ of the electron density of complexes $\left.\mathrm{Ni}(\mathrm{CO})_{3}(\mathrm{PMe})_{3}\right)(\mathrm{a})$

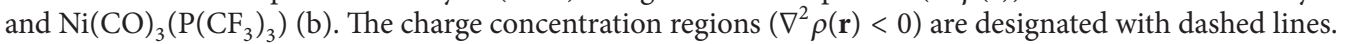

(2.239 ̊). Most complexes reveal $\mathrm{C}_{3}$ symmetry, except $\mathrm{Ni}(\mathrm{CO})_{3}\left(\mathrm{PF}_{3}\right), \mathrm{Ni}(\mathrm{CO})_{3}\left(\mathrm{PMe}_{3}\right)$, and $\mathrm{Ni}(\mathrm{CO})_{3}\left(\mathrm{P}^{\mathrm{t}} \mathrm{Bu}_{3}\right)$, which belong to the $\mathrm{C}_{3 \mathrm{v}}$ point group. It should be noted, however, that the structure of complex $\mathrm{Ni}(\mathrm{CO})_{3}\left(\mathrm{P}\left(\mathrm{CF}_{3}\right)_{3}\right)$ is very close to $\mathrm{C}_{3 \mathrm{v}}$; the small deviation towards $\mathrm{C}_{3}$ is caused by electrostatic repulsion of the highly electronegative fluorine atoms. For the TEPs the $\mathrm{A}_{1} v(\mathrm{CO})$-bands (or $\mathrm{A}$ bands for $\mathrm{C}_{3}$ complexes) are taken into account. The computed wavenumbers show excellent agreement with the experimental ones as they show a systematic deviation of only +6 to $+12 \mathrm{~cm}^{-1}$ except $\mathrm{Ni}(\mathrm{CO})_{3}\left(\mathrm{P}\left(\mathrm{CF}_{3}\right)_{3}\right)$, where the deviation is only $+3 \mathrm{~cm}^{-1}$. That is, the PBEPBE/def2-TZVP(def2-SVP) level of theory seems reliable to predict Tolman's electronic parameters for unknown P-donor ligands.

The QTAIM methodology provides various suitable descriptor for characterizing the bonding (as well as the weak) interactions in transition metal complexes [22, 23]. Detailed information from the electron density distribution can be obtained by the Laplacian of the electron density $\left(\nabla^{2} \rho(\mathbf{r})\right)$ which indicates regions with relative charge concentrations $\left(\nabla^{2} \rho(\mathbf{r})<0\right)$ and charge depletions $\left(\nabla^{2} \rho(\mathbf{r})>\right.$ 0 ) in a molecule. Upon the formation of a chemical bond the Laplacian distribution is no longer spherical, and the distortion of the valence shell charge concentration (VSCC) is characteristic for the atomic interactions. The ellipticity $(\varepsilon)$ obtained from the two negative eigenvalues $\left(\lambda_{1}\right.$ and $\left.\lambda_{2}\right)$ of the Hessian of $\rho(\mathbf{r})$ at the bond critical point (BCP) is the measure of deviation of the density distribution from the axial symmetry of a chemical bond and defined as $\varepsilon=\lambda_{1} / \lambda_{2}$. As expected, ellipticities of zero or very close to zero have been obtained for the Ni-P bond of all the complexes, indicating that the charge distribution along the Ni-P interaction is highly cylindrical.

Comparing the Laplacian of two prototypes of complexes $\mathrm{Ni}(\mathrm{CO})_{3}\left(\mathrm{PMe}_{3}\right)$ and $\mathrm{Ni}(\mathrm{CO})_{3}\left(\mathrm{P}\left(\mathrm{CF}_{3}\right)_{3}\right)$, representing basic and the least basic phosphines, some differences can be observed (see Figure 2). The charge concentration part, depicting the lone pair of phosphorus, is responsible for

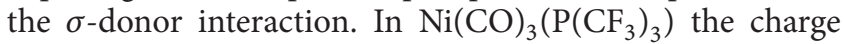
concentration is definitely closer to the $\mathrm{P}$ atom, which is a consequence of the electron withdrawing property of the trifluoromethyl groups. The more compact density distribution is also reflected in the remarkable difference in the NPA charge of phosphorus, being significantly less negative for the complex containing the $\mathrm{P}\left(\mathrm{CF}_{3}\right)_{3}$. The $\mathrm{P}\left(\mathrm{CF}_{3}\right)_{3}$ ligand also takes some electron density from the carbonyl ligands decreasing their partial charges. Interestingly, the Ni center becomes somewhat more negative in this case, preserving some of the charge withdrawn from the carbonyl ligands. 


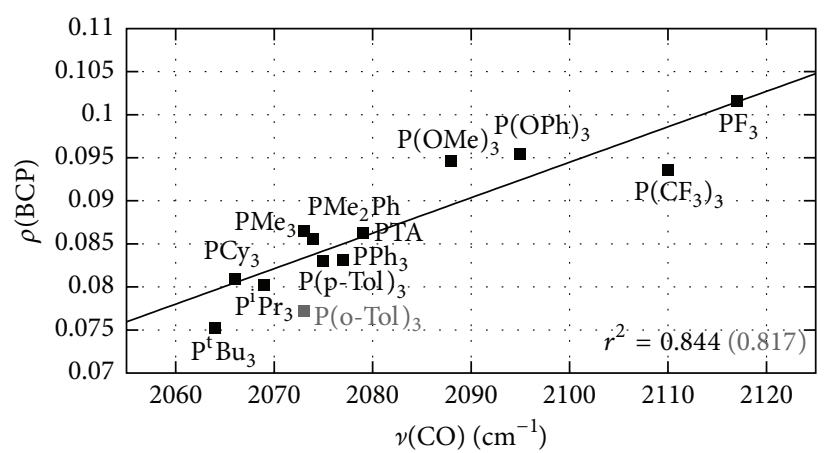

(a)

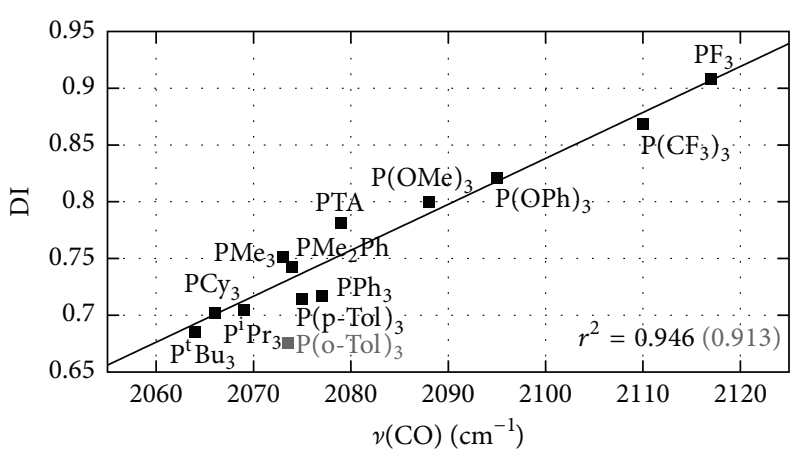

(b)

Figure 3: Relationship between the delocalization index (DI (b)) and the electron density at bond critical points ( $\rho$ (BCP) (a)) and the calculated $\mathrm{A}_{1}$ or $\mathrm{A}$ carbonyl stretching frequencies of $\mathrm{Ni}(\mathrm{CO})_{3} \mathrm{~L}$ complexes. The $r^{2}$ value is given in gray when ligand $\mathrm{P}(\mathrm{o}-\mathrm{Tol})_{3}$ is also taken into account. Correlation equations: $\rho(\mathrm{BCP})=0.000412\left( \pm 5.61 \cdot 10^{-5}\right) \cdot \nu(\mathrm{CO})-0.8043( \pm 0.1273) ; \mathrm{DI}=0.00405( \pm 0.00029) \cdot \nu(\mathrm{CO})-$ $7.6604( \pm 0.6069)$.

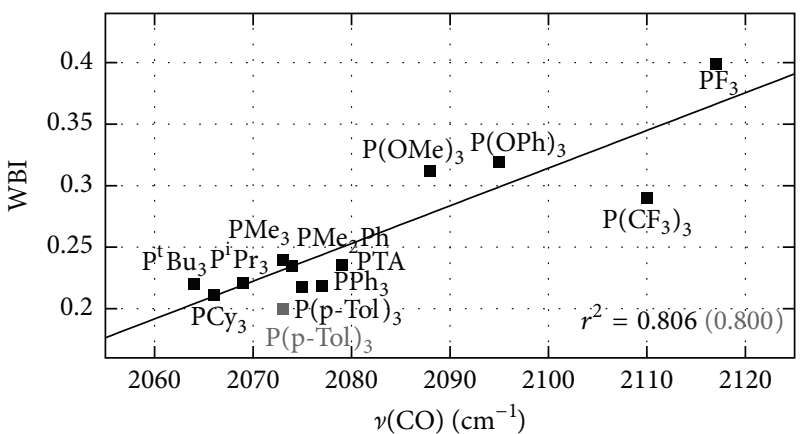

Figure 4: Relationship between the delocalization index Wiberg bond indices (WBI) and the $\mathrm{A}_{1}$ or A carbonyl stretching frequencies of $\mathrm{Ni}(\mathrm{CO})_{3} \mathrm{~L}$ complexes. The $r^{2}$ value is given in gray when ligand $\mathrm{P}(\mathrm{o}-\mathrm{Tol})_{3}$ is also taken into account. Correlation equation: WBI $=0.0031( \pm 0.00047) \cdot v(\mathrm{CO})-6.1196( \pm 0.9886)$.

Based upon the electron density partition scheme of QTAIM, Bader and Stephens introduced the delocalization index denoted here as $\mathrm{DI}(\mathrm{AB})$. This provides the number of electron pairs delocalized between the basins of atoms $A$ and $\mathrm{B}$ [24]. The DI between atomic basins are somewhat related to formal bond orders for an equally shared pair between two atoms in a polyatomic molecule.

The delocalization index for the $\mathrm{Ni}$ and $\mathrm{P}$ atomic basins in $\mathrm{Ni}(\mathrm{CO})_{3} \mathrm{~L}$ complexes is depicted in the function of the computationally determined carbonyl stretching frequency (see Figure 3(b)), with a reasonable linear correlation of $r^{2}=0.946$. Notably worse correlation $\left(r^{2}=0.844\right)$ has been obtained for the electron densities at bond critical points $[\rho(\mathrm{BCP})]$, especially the phosphite ligands, and $\mathrm{P}^{t} \mathrm{Bu}_{3}$ deviates from linearity (Figure 3(a)).

The phosphite ligands show some deviation when the Wiberg bond indices are shown in the function of $\nu(\mathrm{CO})$. The moderate correlation $\left(r^{2}=0.806\right)$ is also a consequence of the behavior of the $\mathrm{P}\left(\mathrm{CF}_{3}\right)_{3}$ ligand, which shows remarkably low value for WBI (see Figure 4). The QTAIM parameters as well as the Wiberg bond indices are compiled in Table 2.
TABLE 2: Computed CO stretching frequencies, electron densities at bond critical points, delocalization indices, and Wiberg bond indices, for $\mathrm{Ni}(\mathrm{CO})_{3} \mathrm{~L}$ complexes.

\begin{tabular}{|c|c|c|c|c|}
\hline Ligand & $\nu(\mathrm{CO})$ & $\rho(\mathrm{BCP})$ & DI (Ni-P) & WBI \\
\hline$\overline{\mathrm{PF}_{3}}$ & 2117 & 0.1016 & 0.9080 & 0.3993 \\
\hline $\mathrm{PMe}_{3}$ & 2073 & 0.0865 & 0.7513 & 0.2396 \\
\hline $\mathrm{PMe}_{2} \mathrm{Ph}$ & 2074 & 0.0856 & 0.7426 & 0.2349 \\
\hline $\mathrm{PPh}_{3}$ & 2077 & 0.0831 & 0.7171 & 0.2188 \\
\hline $\mathrm{P}(\mathrm{p}-\mathrm{Tol})_{3}$ & 2075 & 0.0830 & 0.7141 & 0.2172 \\
\hline $\mathrm{P}(\mathrm{o}-\mathrm{Tol})_{3}$ & 2073 & 0.0772 & 0.6768 & 0.2000 \\
\hline $\mathrm{PCy}_{3}$ & 2066 & 0.0809 & 0.7019 & 0.2114 \\
\hline $\mathrm{P}^{\mathrm{i}} \mathrm{Pr}_{3}$ & 2069 & 0.0802 & 0.7051 & 0.2208 \\
\hline $\mathrm{P}^{t} \mathrm{Bu}_{3}$ & 2064 & 0.0752 & 0.6857 & 0.2197 \\
\hline $\mathrm{P}\left(\mathrm{CF}_{3}\right)_{3}$ & 2110 & 0.0936 & 0.8689 & 0.2903 \\
\hline PTA & 2079 & 0.0863 & 0.7809 & 0.2358 \\
\hline $\mathrm{P}(\mathrm{OMe})_{3}$ & 2088 & 0.0946 & 0.7996 & 0.3117 \\
\hline $\mathrm{P}(\mathrm{OPh})_{3}$ & 2095 & 0.0954 & 0.8209 & 0.3188 \\
\hline
\end{tabular}

In order to scrutinize the $\sigma$-donor properties of P-donor ligands the ETS-NOCV methodology has been selected, where ETS stands for Extended Transition State. Within this approach the interaction energy between the selected ligand and the remaining part of the complex is decomposed into chemically meaningful components representing different steps toward the formation of the molecule from its fragments. When the orbital interaction part is expressed in NOCV, rather than orthogonalized fragment orbitals, only a few complementary pairs will contribute to the interaction energy in a significant amount. This provides a better visualization of the deformation densities and of their energy contributions to the bond energy $[9,25,26]$.

The deformation density $\Delta \rho_{\text {orb }}^{\sigma}$ representing the $\sigma$ donor interaction in the selected complex $\mathrm{Ni}(\mathrm{CO})_{3}\left(\mathrm{PMe}_{3}\right)$ is depicted in Figure 5. The interaction energies that resulted from the energy decomposition as well as the energy components for the $\sigma$-donor interaction are compiled in Table 3 . 


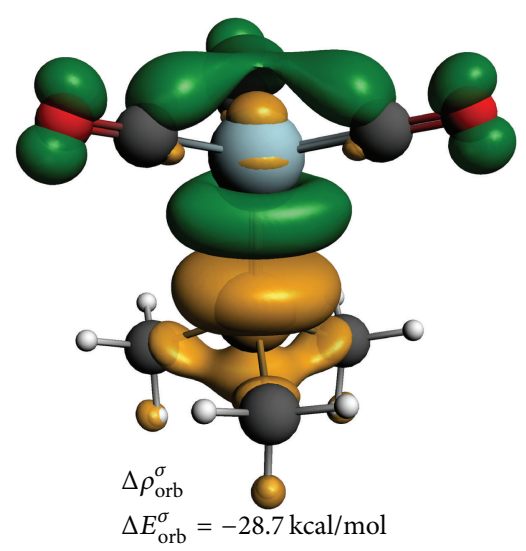

$\Delta \rho>0$

$\Delta \rho<0$
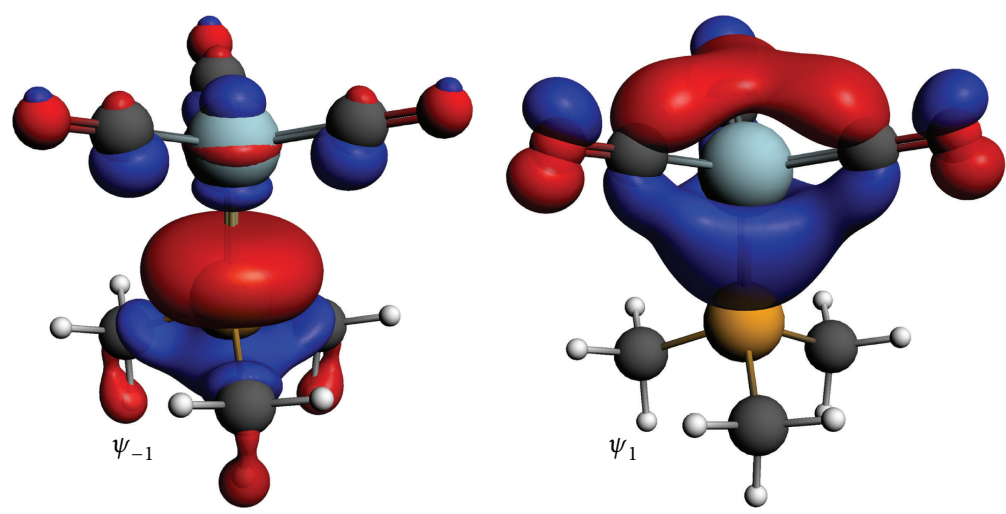

(a)

$\Delta \rho_{\text {orb }}^{\sigma}=-0.61 \cdot\left(\psi_{-1}\right)^{2}+0.61 \cdot\left(\psi_{1}\right)^{2}$

(b)

FIGURE 5: NOCV deformation density (a) and the corresponding complementary NOCV orbitals for the complex $\mathrm{Ni}(\mathrm{CO})_{3}(\mathrm{PMe})_{3}$.

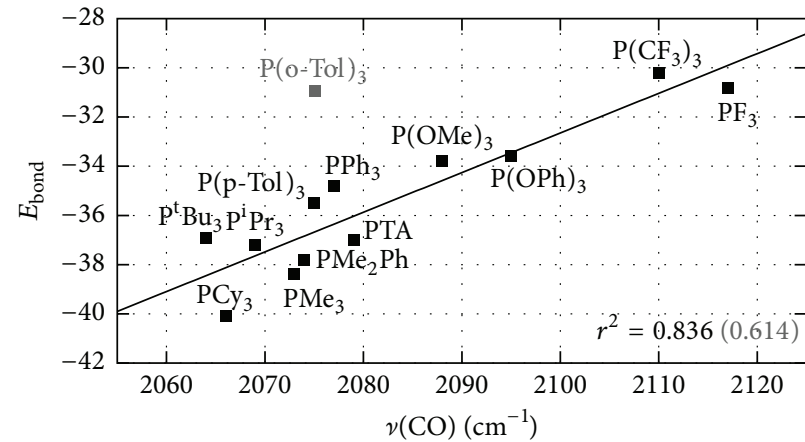

(a)

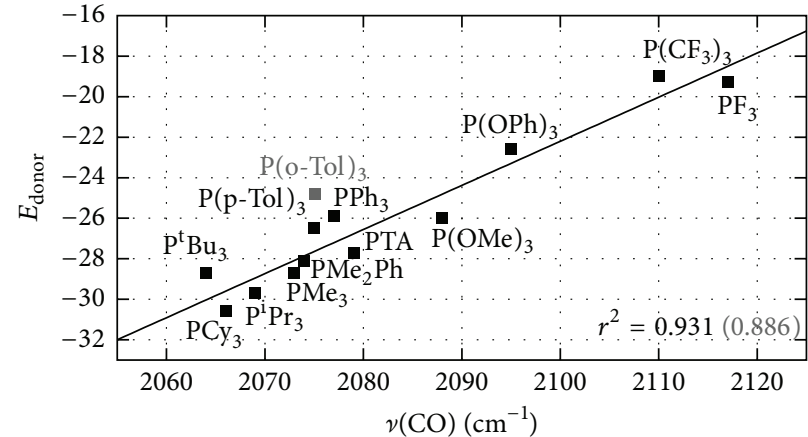

(b)

FIGURE 6: Relationship between the bonding energy between fragments (a) and its component for the $\sigma$-donor interaction (b) and the $\mathrm{A}_{1}$ or A carbonyl stretching frequencies of $\mathrm{Ni}(\mathrm{CO})_{3} \mathrm{~L}$ complexes. The $r^{2}$ value is given in gray when ligand $\mathrm{P}(\mathrm{o} \text {-Tol })_{3}$ is also taken into account. Correlation equations: $E_{\text {bond }}=0.1612( \pm 0.0226) \cdot \nu(\mathrm{CO})-371.1( \pm 47.0) ; E_{\text {donor }}=0.2177( \pm 0.0188) \cdot \nu(\mathrm{CO})-479.30( \pm 39.09)$.

The deformation density can be expressed as a sum of pairs of complementary NOCV orbitals $\left(\psi_{-k}\right.$ and $\left.\psi_{k}\right)$ corresponding to eigenvalues equal in absolute value but opposite in signs [27]. The complementary pairs of NOCV define the channels where the electron charge transfers will take place between the molecular fragments, that is, from the coordinating lone pair of phosphorus towards the $\pi^{*}$ orbitals of carbonyl ligands.

The energy components of the $\sigma$-donor interaction for the selected ligands are in a good linear correlation with computed $v(\mathrm{CO})$-s with $r^{2}=0.931$. Somewhat more loose relationship has been found for the bond energies between the metal containing fragment and the P-donor ligands $\left(r^{2}=\right.$ 0.836) (see Figure 6). Strong deviation has been obtained, however, when the sterically demanding ligand $\mathrm{P}(\mathrm{o}-\mathrm{Tol})_{3}$ was included in the training set. Thus, the deformation density $\Delta \rho_{\text {orb }}^{\sigma}$ representing the $\sigma$-donor interaction is also a suitable quantum chemical descriptor for the prediction of Tolman's
TABLE 3: Computed CO stretching frequencies, donor energy components, and interaction energies between fragments, determined by $\mathrm{NOCV}$ calculations for $\mathrm{Ni}(\mathrm{CO})_{3} \mathrm{~L}$ complexes.

\begin{tabular}{|c|c|c|c|}
\hline Ligand & $v(\mathrm{CO})$ & $E_{\text {donor }}$ & $E_{\text {bonding }}$ \\
\hline $\mathrm{PF}_{3}$ & 2117 & -19.3 & -30.8 \\
\hline $\mathrm{PMe}_{3}$ & 2073 & -28.7 & -38.4 \\
\hline $\mathrm{PMe}_{2} \mathrm{Ph}$ & 2074 & -28.1 & -37.8 \\
\hline $\mathrm{PPh}_{3}$ & 2077 & -25.9 & -34.8 \\
\hline $\mathrm{P}(\mathrm{p}-\mathrm{Tol})_{3}$ & 2075 & -26.5 & -35.5 \\
\hline $\mathrm{P}(\mathrm{o}-\mathrm{Tol})_{3}$ & 2075 & -24.8 & -31.0 \\
\hline $\mathrm{PCy}_{3}$ & 2066 & -40.1 & -30.6 \\
\hline $\mathrm{P}^{\mathrm{i}} \mathrm{Pr}_{3}$ & 2069 & -29.7 & -37.2 \\
\hline $\mathrm{P}^{\mathrm{t}} \mathrm{Bu}_{3}$ & 2064 & -28.7 & -36.9 \\
\hline $\mathrm{P}\left(\mathrm{CF}_{3}\right)_{3}$ & 2110 & -19 & -30.2 \\
\hline PTA & 2079 & -27.7 & -37.0 \\
\hline $\mathrm{P}(\mathrm{OMe})_{3}$ & 2088 & -26.0 & -36.4 \\
\hline $\mathrm{P}(\mathrm{OPh})_{3}$ & 2095 & -22.6 & -33.6 \\
\hline
\end{tabular}


electronic parameters for new P-donor ligands with not particularly high steric bulk.

\section{Concluding Remarks}

In the present study some quantum chemical descriptors have been scrutinized in order to examine how suitable they are for predicting Tolman's electronic parameters for various Pdonor ligands. The delocalization index from the QTAIM methodology and the interaction energy associated with the NOCV deformation density for the $\sigma$-donor interaction are the two descriptors which reveal reasonable linear correlation with the computed carbonyl stretching frequencies. Whereas it is the expected behavior for the NOCV energy contributions, this is somewhat surprising for DI-s, meaning that they are much more directly connected to the donor strength of the ligand than other descriptors, such as $\rho(\mathrm{BCP})$ $s$ and Wiberg bond indices. It has been also found that the PBEPBE functional in combination with the def2-SVP basis set (def2-TZVP for the nickel atom) gives accurate predictions for the $A_{1}$ (or $A$ ) carbonyl stretching frequencies in nickel-tricarbonyl complexes. The significant increase of steric demand of the ligand, represented by $\mathrm{P}(\mathrm{o}-\mathrm{Tol})_{3}$, causes a deviation from linearity for all descriptors, albeit in a different extent.

\section{Competing Interests}

The authors declare that there is no conflict of interests regarding the publication of this article and regarding the funding that they have received.

\section{Acknowledgments}

The authors thank the Hungarian Scientific Research Fund (K113177) and Environmental Industry Related Innovative Trans- and Interdisciplinary Research Team Development in the University of Pécs Knowledgebase (SROP-4.2.2.D15/1/KONV-2015-0015) for the financial support. This paper was supported by the János Bolyai Research Scholarship of the Hungarian Academy of Sciences. The authors also thank the Supercomputer Center of the National Information Infrastructure Development (NIIF) Program.

\section{References}

[1] W. Strohmeier and F. Müller, "Klassifizierung phosphorhaltiger Liganden in Metallcarbonyl-Derivaten nach der $\pi$ Acceptorstärke," Chemische Berichte, vol. 100, no. 9, pp. 28122821, 1967.

[2] C. A. Tolman, "Steric effects of phosphorus ligands in organometallic chemistry and homogeneous catalysis," Chemical Reviews, vol. 77, no. 3, pp. 313-348, 1977.

[3] A. Roodt, S. Otto, and G. Steyl, "Structure and solution behaviour of rhodium(I) Vaska-type complexes for correlation of steric and electronic properties of tertiary phosphine ligands," Coordination Chemistry Reviews, vol. 245, no. 1-2, pp. 121-137, 2003.
[4] A. Muller, S. Otto, and A. Roodt, "Rapid phosphorus(III) ligand evaluation utilising potassium selenocyanate," Dalton Transactions, no. 5, pp. 650-657, 2008.

[5] C. H. Suresh and N. Koga, "Quantifying the electronic effect of substituted phosphine ligands via molecular electrostatic potential," Inorganic Chemistry, vol. 41, no. 6, pp. 1573-1578, 2002.

[6] H.-Y. Liu, K. Eriks, A. Prock, and W. P. Giering, "Quantitative Analysis of Ligand Effects (QALE). Systematic study of ironphosphorus bond lengths and their relationship to steric thresholds," Organometallics, vol. 9, no. 6, pp. 1758-1766, 1990.

[7] J. Bartholomew, A. L. Fernandez, B. A. Lorsbach, M. R. Wilson, A. Prock, and W. P. Giering, "Comments on coupling graphical and regression analyses of ligand effect data," Organometallics, vol. 15, no. 1, pp. 295-301, 1996.

[8] R. F. W. Bader, Atoms in Molecules-A Quantum Theory, Oxford University Press, Oxford, UK, 1990.

[9] M. P. Mitoraj, A. Michalak, and T. Ziegler, "A combined charge and energy decomposition scheme for bond analysis," Journal of Chemical Theory and Computation, vol. 5, no. 4, pp. 962-975, 2009.

[10] J. P. Perdew, K. Burke, and M. Ernzerhof, "Generalized gradient approximation made simple," Physical Review Letters, vol. 77, no. 18 , pp. 3865-3868, 1996.

[11] M. J. Frisch, G. W. Trucks, H. B. Schlegel et al., Gaussian 09 Revision D.01, Gaussian, Wallingford, Conn, USA, 2009.

[12] J. M. Tukacs, D. Király, A. Strádi et al., "Efficient catalytic hydrogenation of levulinic acid: a key step in biomass conversion," Green Chemistry, vol. 14, no. 7, pp. 2057-2065, 2012.

[13] F. Weigend and R. Ahlrichs, "Balanced basis sets of split valence, triple zeta valence and quadruple zeta valence quality for $\mathrm{H}$ to Rn: design and assessment of accuracy," Physical Chemistry Chemical Physics, vol. 7, no. 18, pp. 3297-3305, 2005.

[14] T. A. Keith, AIMAll (Version 15.05.18), TK Gristmill Software, Overland Park, Kan, USA, 2015, http://aim.tkgristmill.com.

[15] A. E. Reed, L. A. Curtiss, and F. Weinhold, "Intermolecular interactions from a natural bond orbital, donor-acceptor viewpoint," Chemical Reviews, vol. 88, no. 6, pp. 899-926, 1988.

[16] G. te Velde, F. M. Bickelhaupt, S. J. van Gisbergen et al., "Chemistry with ADF" Journal of Computational Chemistry, vol. 22, no. 9, pp. 931-967, 2001.

[17] ADF2012, SCM, Theoretical Chemistry, Vrije Universiteit, Amsterdam, The Netherlands, 2012, http://www.scm.com.

[18] B. C. Taverner, "Improved algorithm for accurate computation of molecular solid angles," Journal of Computational Chemistry, vol. 17, no. 14, pp. 1612-1623, 1996.

[19] J. M. Smith and N. J. Coville, "Steric parameters of conformationally flexible ligands from X-ray structural data. 2. $\mathrm{P}(\mathrm{OR})_{3}$ ligands in multiple ligand environments," Organometallics, vol. 20, no. 6, pp. 1210-1215, 2001.

[20] D. J. Darensbourg, T. J. Decuir, N. W. Stafford et al., "Watersoluble organometallic compounds. 6.1 synthesis, spectral properties, and crystal structures of complexes of 1,3,5-Triaza-7phosphaadamantane with group 10 metals," Inorganic Chemistry, vol. 36, no. 19, pp. 4218-4226, 1997.

[21] O. Kuhl, "Predicting the net donating ability of phosphinesdo we need sophisticated theoretical methods?" Coordination Chemistry Reviews, vol. 249, no. 5-6, pp. 693-704, 2005.

[22] F. Cortés-Guzmán and R. F. W. Bader, "Complementarity of QTAIM and MO theory in the study of bonding in donoracceptor complexes," Coordination Chemistry Reviews, vol. 249, no. 5-6, pp. 633-662, 2005. 
[23] T. Kégl, R. Ponec, and L. Kollár, "Theoretical insights into the nature of nickel-carbon dioxide interactions in $\mathrm{Ni}\left(\mathrm{PH}_{3}\right)_{2}\left(\eta_{2}-\right.$ $\mathrm{CO}_{2}$ )," Journal of Physical Chemistry A, vol. 115, no. 45, pp. 12463-12473, 2011.

[24] R. F. W. Bader and M. E. Stephens, "Spatial localization of the electronic pair and number distributions in molecules," Journal of the American Chemical Society, vol. 97, no. 26, pp. 7391-7399, 1975.

[25] A. Michalak, M. Mitoraj, and T. Ziegler, "Bond orbitals from chemical valence theory," The Journal of Physical Chemistry A, vol. 112, no. 9, pp. 1933-1939, 2008.

[26] M. P. Mitoraj and A. Michalak, " $\sigma$-Donor and $\pi$-acceptor properties of phosphorus ligands: an insight from the natural orbitals for chemical valence," Inorganic Chemistry, vol. 49, no. 2, pp. 578-582, 2010.

[27] M. Mitoraj and A. Michalak, "Donor-acceptor properties of ligands from the natural orbitals for chemical valence," Organometallics, vol. 26, no. 26, pp. 6576-6580, 2007. 

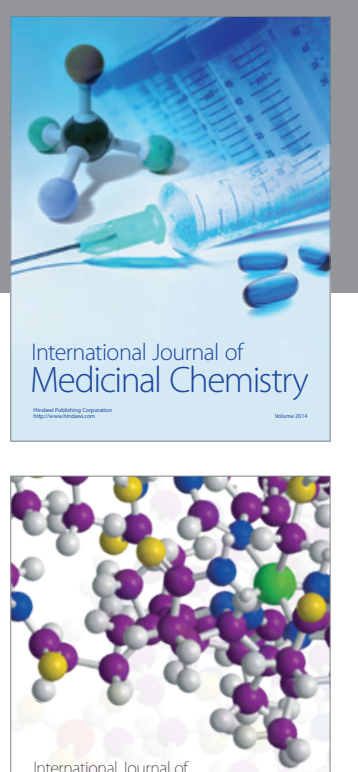

Carbohydrate Chemistry

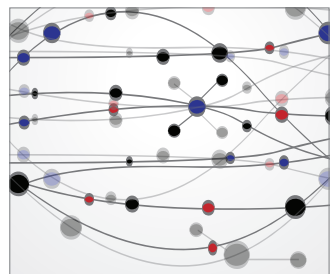

The Scientific World Journal
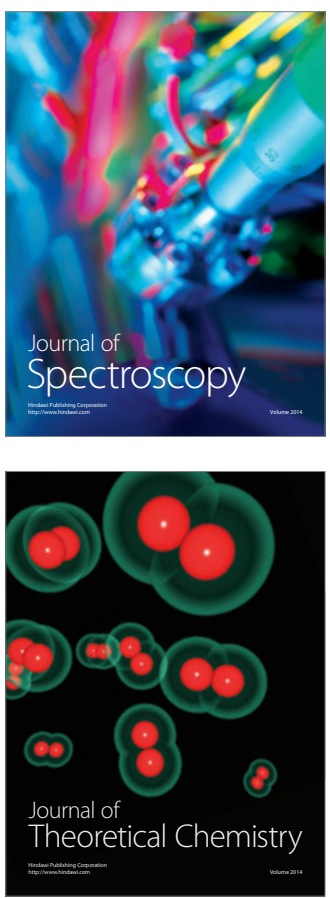
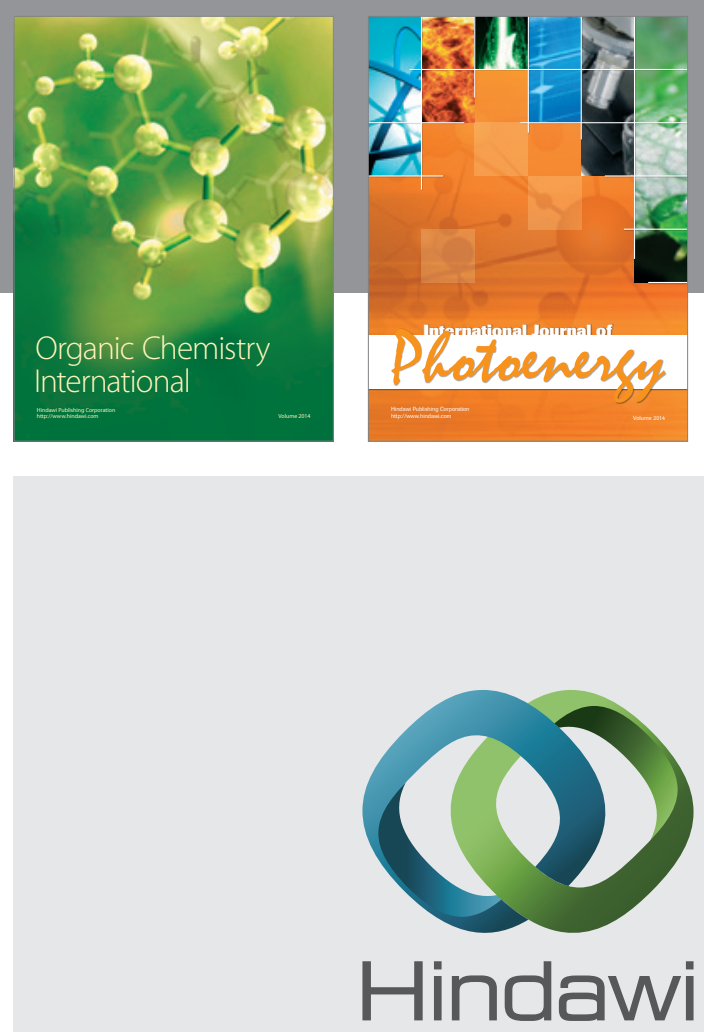

Submit your manuscripts at

http://www.hindawi.com

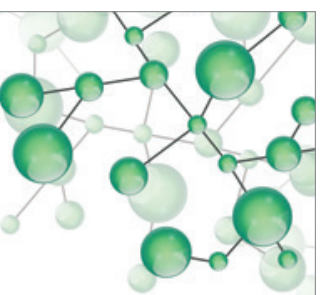

International Journal of

Inorganic Chemistry

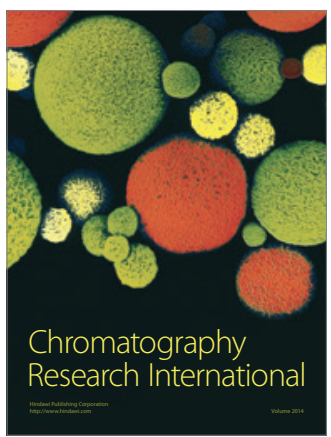

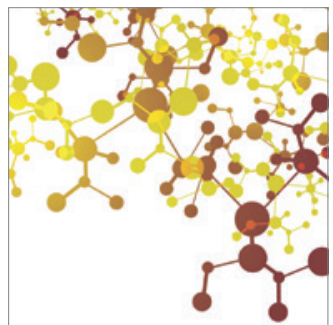

Applied Chemistry
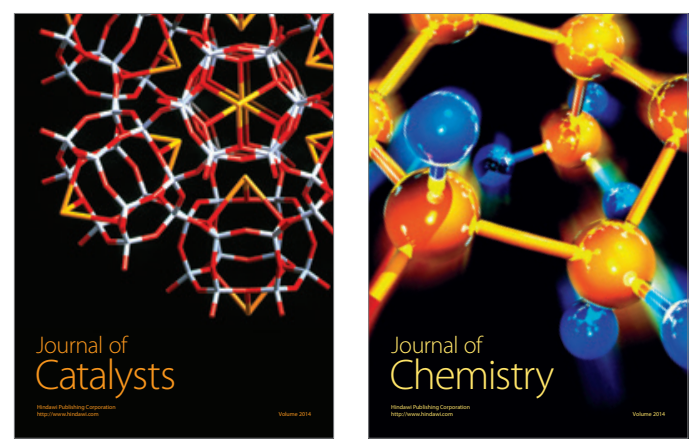
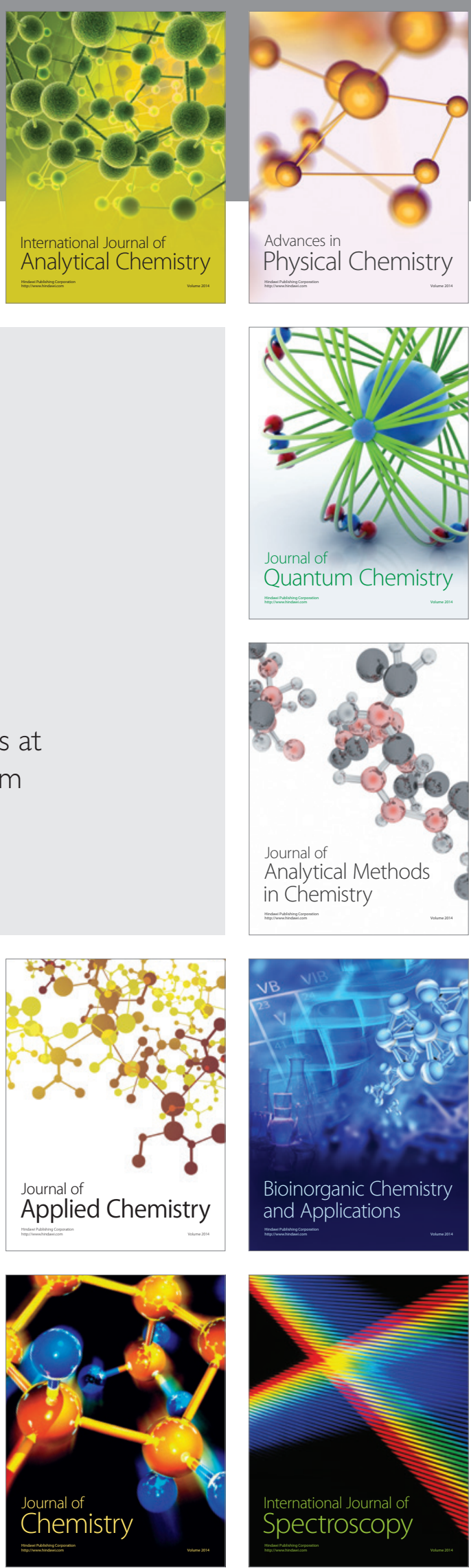